\title{
N2 Sleep to Total Sleep Time Ratio Measurement
}

National Cancer Institute

\section{Source}

National Cancer Institute. N2 Sleep to Total Sleep Time Ratio Measurement. NCI

Thesaurus. Code C156556.

The determination of the ratio of N2 sleep time compared to total sleep time. The measurement may be expressed as a ratio or percentage. 